\title{
Política monetária, inflação e crescimento econômico: a influência da reputação da autoridade monetária sobre a economia $^{1}$
}

\author{
Gabriel Caldas Montes ${ }^{2}$
}

\begin{abstract}
Resumo
O presente trabalho tem como principal objetivo mostrar que a política monetária, quando conduzida por meio de uma regra de manipulação da taxa de juros voltada exclusivamente para controlar a inflação (em um regime de metas para a inflação), embora consiga atingir tal objetivo, apresenta um resultado pior se comparada a uma política monetária que seja implementada, também, para atingir uma meta para o nível do produto. O modelo proposto enfatiza: o papel das expectativas, o papel da autoridade monetária por meio de sua função de reação à luz da hipótese de não neutralidade da moeda e a influência da reputação da autoridade monetária sobre os resultados observados na economia.
\end{abstract}

Palavras-chave: Reputação; Inflação - Metas; Crescimento econômico.

Abstract

Monetary policy, inflation and economic growth: the influence of the monetary authority's reputation upon the economy

The following paper aims to show that, although a monetary policy, which merely seeks to control inflation through an interest rate rule (under inflation targeting), may reach such a goal, it will present a worst outcome whether compared to a monetary policy which also seeks an output target. The proposed model highlights: the role of expectations, the role of monetary policy through its reaction function in the light of non-neutrality of money hypothesis and, the influence of monetary authority reputation on the economy.

Key words: Reputation; Inflation targeting; Economic growth.

JEL E31, E52, E58, E61.

\section{Introdução}

Atualmente, diversos países, dentre eles o Brasil, utilizam o regime de metas para a inflação como principal guia de condução da política monetária. ${ }^{3}$

(1) Trabalho recebido em abril de 2007 e aprovado em maio de 2008. Agradeço os profícuos comentários dos professores Carmem Feijó e Helder Ferreira de Mendonça, ambos da Universidade Federal Fluminense (UFF) e das sugestões proferidas pelos pareceristas anônimos que, no entanto, não são responsáveis por falhas e omissões que persistam.

(2) Professor da Universidade Federal Fluminense (UFF), Niterói, RJ, Brasil. E-mail: gabrielmontesuff@yahoo.com.br.

(3) Esse regime foi implementado, inicialmente, na Nova Zelândia, Reino Unido e Canadá, sendo posteriormente adotado em países como Austrália, Espanha, Finlândia e Suécia. Ao longo dos últimos anos, diversos países implementaram o regime de metas de inflação como uma espécie de novo paradigma a ser seguido para a condução da política monetária. O Brasil implementou esse regime em junho de 1999, após a opção pela mudança em seu regime cambial, devido aos sucessivos ataques especulativos que vinham sofrendo os países que adotaram uma estratégia de âncora cambial como forma de combater o processo inflacionário. 
Seus proponentes advogam que esse regime resulta em uma melhor - e mais crível - maneira de conduzir a política monetária, levando a um maior nível de transparência e responsabilidade da autoridade monetária, além de se tornar com o tempo a melhor âncora para as expectativas de inflação. Embora alguns trabalhos apontem evidências empíricas favoráveis à existência de uma relação entre o regime de metas para a inflação e os resultados observados para a inflação e para as expectativas de inflação, sugerindo que, após sua implementação, a inflação tendeu a se manter em um patamar baixo e estável, essas evidências são contestadas por estudos que apontam resultados não conclusivos. ${ }^{4}$

Acerca do regime, segundo o mainstream, para que seja bem-sucedido em manter a inflação em um patamar baixo e estável, implicando, consequentemente, uma menor variabilidade do produto, deve ser acompanhado das seguintes características: (i) o governo deve anunciar uma meta numérica para a taxa de inflação; (ii) o alcance da meta deve ser obtido por meio de manipulações na taxa de juros; (iii) as expectativas para a inflação devem ser utilizadas como metas intermediárias; (iv) dado que a política monetária é o instrumento central de alcance da meta, deve ser conduzida de maneira transparente; (v) a política monetária deve ser conduzida por um banco central independente; e (vi) a política monetária deve ter como objetivo único o controle da inflação, ignorando os efeitos sobre as demais variáveis de desempenho da economia.

Com relação às características citadas acima, devemos lembrar que, teoricamente, existem muitas controvérsias quanto aos efeitos da política monetária sobre a economia, assim como a respeito da forma de atuação da autoridade monetária e dos objetivos que persegue. Ao contrapor o conceito de não neutralidade da moeda ao conceito de neutralidade da moeda apresentado pelo mainstream, podem ser identificadas quatro principais metas finais a serem perseguidas, em conjunto ou isoladamente, pela política monetária: controle da inflação; expansão do nível de atividade econômica; redução da taxa de desemprego; e manutenção da estabilidade do sistema financeiro. Em termos teóricos, aceitar ou rejeitar determinadas hipóteses, como por exemplo, a neutralidade da moeda, ou os motivos que explicam a preferência pela liquidez, ou a maneira como se dá o processo inflacionário, ou como são formadas as expectativas dos agentes, traz consequências diretas sobre os resultados dos modelos quando analisada a condução da política monetária.

(4) Para um estudo comparativo acerca das evidências empíricas realizadas para o regime de metas de inflação, ver Angeriz e Arestis (2006), em artigo no qual levantam a seguinte questão: teria o regime de metas de inflação alguma influência sobre a inflação? O trabalho de Angeriz e Arestis cita tanto as referências de trabalhos que apontam para resultados favoráveis ao regime como também aponta outras evidências empíricas controversas. 
Assim, o presente trabalho tem como principal objetivo mostrar que a política monetária, quando conduzida por uma regra de manipulação da taxa de juros voltada exclusivamente para controlar a inflação (em um regime de metas para a inflação), embora consiga atingir tal objetivo, apresenta um resultado pior se comparada a uma política monetária que seja implementada, também, para atingir uma meta para o nível do produto. $\mathrm{O}$ modelo elaborado para mostrar tais resultados enfatiza: o papel das expectativas, o papel da autoridade monetária por meio de sua função de reação à luz da hipótese de não neutralidade da moeda e a influência da reputação da autoridade monetária sobre os resultados observados na economia.

Para isso, o modelo destaca os processos inflacionários de demanda e de custos que podem ser observados na economia, com intuito de reforçar a ideia de que, para cada diagnóstico inflacionário, uma política econômica específica deva ser implementada. ${ }^{5}$ A crítica reside na questão envolvendo a subutilização da política monetária, sustentada pelo princípio da neutralidade da moeda - a qual orienta a política monetária a ser conduzida por meio de uma regra preocupada única e exclusivamente com os resultados referentes ao comportamento da inflação, conferindo pouca ou quase nenhuma atenção ao produto e à renda.

A principal crítica, portanto, não se encontra relacionada a adotar ou não metas para a inflação - explícitas ou implícitas - mas sim, à regra de política monetária que se utiliza somente de manipulações da taxa de juros, e que por sua vez, ignora os determinantes do processo de formação de preços, os determinantes (de um modo geral) do comportamento da inflação e a influência da política monetária sobre o lado real da economia. Nesse sentido, o trabalho busca tornar compatível a adoção de metas para a inflação com crescimento econômico, destacando o papel que, de fato, deve exercer a política monetária e a importância da forma de atuação da autoridade monetária por meio de suas políticas - ou seja, de sua reputação.

Além dessa introdução, o trabalho encontra-se dividido da seguinte maneira: a Seção 1 apresenta um modelo caracteristicamente ortodoxo de funcionamento da economia, seus principais resultados e, por conseguinte, sua aceitação por parte do "novo consenso" macroeconômico; além disso, a seção mostra, também, as controvérsias existentes acerca desse modelo; a Seção 2 expõe um modelo capaz de apontar a influência da política monetária sobre o lado real e nominal da economia, demonstrando que os resultados obtidos para o produto são melhores quando a autoridade monetária se preocupa em reagir aos desvios do produto em relação a uma meta para o produto e quando a autoridade monetária

(5) O modelo descarta de sua análise os movimentos na inflação decorrentes do processo de indexação dos preços da economia a algum tipo de mecanismo de correção monetária, que deu origem à chamada inflação inercial, buscando enfatizar, de fato, os processos inflacionários oriundos de pressões de demanda e de custos. 
cria e fortalece uma reputação de estar preocupada, também, com os resultados que se observam no lado real; na sequencia as considerações finais.

\section{1 "Novo consenso" macroeconômico e metas de inflação}

A compatibilidade entre pensamento macroeconômico tradicional (ou mainstream macroeconômico) e a adoção de regras monetárias sob o regime de metas de inflação pode ser facilmente observada por meio de modelos elaborados sob um "novo consenso" macroeconômico (Goodfriend; King, 1997; King, 2000; Romer, 2000; Taylor, 2000; Goodfriend, 2004; Woodford, 2003). Tais modelos são entendidos pelos seus proponentes como sendo representativos daqueles utilizados pelas principais autoridades monetárias, em que apresentam fundamentalmente as seguintes características: utilizam-se das hipóteses de expectativas racionais, neutralidade da moeda no longo prazo, existência de um processo de barganha no mercado de trabalho acerca do salário real, equilíbrio determinado pela oferta (ou seja, a demanda agregada é irrelevante para a determinação dos valores de equilíbrio das variáveis reais) e processo inflacionário explicado por pressões de demanda (excesso de demanda agregada é a principal fonte de inflação). Essas características, no que diz respeito ao comportamento da inflação e sua relação com o lado real da economia, podem ser expressas sob a forma de uma curva de Phillips - representativa do processo inflacionário consistente com a hipótese de taxa natural.

Quanto à utilização da curva de Phillips $(\mathrm{CP})$ como guia de conduta da política econômica, sua prática emergiu por meio dos modelos elaborados pela síntese neoclássica. A necessidade de se adicionar um bloco explicativo para o comportamento dos preços e salários dentro do arcabouço IS-LM, de modo a explorar as implicações das políticas econômicas tanto sobre o lado real quanto o lado nominal da economia levou o modelo a ser conhecido como IS-LM-CP. Contudo, a ocorrência de elevados níveis de desemprego com elevada inflação na década de 1970 levou os macroeconomistas a questionarem aspectos teóricos e quantitativos que sustentavam o modelo IS-LM-CP. Questões fundamentais foram levantadas por parte do pensamento novo-clássico emergente - liderado por Lucas e seguido por economistas que apoiavam a revolução das expectativas racionais acerca da validade do modelo e do receituário de políticas econômicas que sugeria. O modelo IS-LM-CP passou a ser visto por esses economistas (a exemplo, Lucas, 1972a, 1972b, 1976, 1980; Sims, 1980; Leeper; Sims, 1994) como sendo inconsistente com o comportamento otimizador de famílias e firmas, sendo criticado não somente por não utilizar microfundamentos como um guia para a especificação das equações estimadas, como também por evitar questões centrais de identificação. 
Recentemente, o desenvolvimento de uma nova escola de pensamento baseada nesse "novo consenso" - vem ganhando evidência por meio da combinação de elementos clássicos com elementos keynesianos em modelos microfundamentados que aplicam otimização intertemporal e hipótese de expectativas racionais, movendo a macroeconomia em direção a uma "Nova Síntese Neoclássica". O "novo modelo IS-LM" é o resultado desse novo programa de pesquisa que emerge, incorporando em sua estrutura expectativas racionais e derivações microfundamentadas. O modelo, embora se encontre designado a descrever o comportamento de variáveis macroeconômicas que entram na maioria das discussões de políticas econômicas, não deixa de ser elaborado sob bases microeconômicas.

Também conhecido como "modelo IS-LM expectacional", pois em suas equações são incluídos termos expectacionais, o modelo tem como propósito, por exemplo, fortalecer conclusões sobre a condução da política monetária em quatro grandes áreas:

(1) a necessidade de utilização de metas para inflação, sob a justificativa de que a política monetária que conduz a inflação para patamares baixos e estáveis, consequentemente, levará e manterá o nível de atividade econômica próximo de sua capacidade;

(2) o comportamento da taxa de juros sob metas de inflação, pois a taxa de juros real (equivalente à taxa de juros nominal menos a inflação esperada) é um preço relativo intertemporal crucial, o qual aumenta quando se espera um aumento no crescimento da atividade real, e se reduz quando há uma desaceleração da economia, ou seja, o banco central manipula (aumenta/diminui) a taxa de juros nominal de acordo com movimentos (aumentos/reduções, respectivamente) na taxa de crescimento esperado do produto da economia;

(3) as limitações da política monetária, suscitando uma autoridade monetária incapaz de sustentar desvios permanentes do produto de seu nível potencial, devendo, portanto, se ater a regras restritas compatíveis a um equilíbrio único sob expectativas racionais; e

(4) os efeitos da política monetária sob a economia à luz do debate "regras versus discrição".

Romer (2000), embora também analise a condução da política monetária à luz dessas quatro grandes áreas, argumenta que atualmente a maioria dos bancos centrais confere pouca atenção aos agregados monetários ao conduzir a política monetária. Nesse sentido, sugere um modelo alternativo que não incorpora a curva 
LM, mas sim a hipótese de que a autoridade monetária segue uma regra para o comportamento da taxa de juros real. ${ }^{6}$ De acordo com Romer (2000, p. 154):

This assumption is a vastly better description of how central banks behave than the assumption that they follow a money supply rule. Central banks in almost all industrialized countries focus on the interest rate on loans between banks in their shot-run policy-making.

Sendo assim, o modelo exposto nessa seção como representativo do "novo consenso macroeconômico" segue as ideias contidas em Allsopp e Vines (2000), Taylor (2000) e Romer (2000), sendo apresentado de forma semelhante a como é feita em Lavoie (2006) e Setterfield (2006). Ou seja, o modelo encontra-se estruturado em três equações fundamentais: uma equação IS, uma equação da curva de Phillips e uma função de reação da autoridade monetária. Assim, busca analisar o equilíbrio macroeconômico quando a autoridade monetária conduz a política monetária por meio de uma regra, sob o regime de metas de inflação.

\subsection{O modelo}

O modelo representativo do novo consenso pode ser resumido por meio das seguintes equações:

$$
\begin{aligned}
& y=A-\delta . r \\
& \pi=\pi_{-1}+\alpha\left(y-y_{n}\right) \\
& \dot{r}=\beta\left(y-y_{n}\right)+\gamma\left(\pi-\pi^{T}\right)
\end{aligned}
$$

A equação (1) representa o equilíbrio no mercado do produto (equação IS), a equação (2) expressa o comportamento da inflação por meio da curva de Phillips, incorporando a hipótese de taxa natural, e a equação (3) é uma função de reação da autoridade monetária. O nível do produto real e o nível natural do produto real são expressos respectivamente por $y$ e $y_{n}$; a taxa de juros real é expressa por $r$; a taxa de inflação e a meta para a taxa de inflação são representadas por $\pi$ e $\pi^{T}$, respectivamente; o termo $A$ expressa os componentes autônomos, incluindo a política fiscal.

De modo a analisar os resultados a serem obtidos e a estabilidade na configuração de equilíbrio do modelo, assim como sua compatibilidade com o regime de metas para a inflação, as equações devem ser reduzidas a um sistema de equações diferenciais (no tempo). Nesse sentido, diferenciando a equação (1) no tempo e considerando $\dot{A}=0$, obtém-se

(6) Essa hipótese ajuda a evitar as complicações e controvérsias que emergem dentro da estrutura IS-LM envolvendo a utilização das taxas de juros real (para a IS) e nominal (para a LM). Acerca das demais vantagens sugeridas pelo modelo proposto por Romer, ver Romer (2000). 
Política monetária, inflação e crescimento econômico: a influência da reputação da autoridade monetária...

$\dot{y}=-\delta . \dot{r}$

Por sua vez, combinando a equação (4) com a equação (3) chega-se a

$$
\dot{y}=-\delta \beta\left(y-y_{n}\right)-\delta \gamma\left(\pi-\pi^{T}\right)
$$

Sendo $\dot{\pi}=\pi-\pi_{-1}$, então, pela equação (2), obtém-se

$$
\dot{\pi}=\alpha\left(y-y_{n}\right)
$$

O equilíbrio é obtido nas equações (5) e (6) quando não ocorre variação na taxa de inflação, ou seja, a inflação está estável, e quando não ocorre variação no nível do produto real, isto é, quando se encontra em estado estacionário compatível com o nível natural. Essa situação pode ser expressa por $\dot{y}=\dot{\pi}=0$, o que leva por meio da equação (6) a $y=y_{n}$, e por meio da equação (5) à seguinte expressão:

$$
y=y_{n}+\frac{\gamma}{\beta} \pi^{T}-\frac{\gamma}{\beta} \pi
$$

Como $y=y_{n}$, então, substituindo na equação (7), conclui-se que

$$
\pi=\pi^{T}
$$

A estabilidade da configuração de equilíbrio pode ser verificada por meio da análise dos jacobianos obtidos das matrizes representativas do sistema de equações formado pelas equações (5) e (6). ${ }^{7}$

O resultado fundamental extraído do modelo é que a autoridade monetária, além de estabelecer uma meta de inflação explícita, ao agir de acordo com a sua função de reação - equação (3) - assegura que a meta de inflação seja parte de uma configuração de equilíbrio agregado na qual a economia irá, sempre, em direção $\left(y=y_{n}\right.$ e $\pi=\pi^{T}$ ), seja qual for a perturbação.

\subsection{Controvérsias acerca do modelo}

O modelo, no entanto, considera o comportamento da inflação explicado somente por pressões de demanda - desvios do produto em relação ao seu nível natural - assim como sugere a manipulação de somente um único instrumento (taxa de juros) quando ocorrem variações no hiato do produto responsáveis por pressões de demanda ou quando a inflação se desvia da meta de inflação. Ou seja, o modelo desconsidera as pressões de custo sobre a inflação, a influência das

(7) O presente trabalho não tem como objetivo enfatizar e aprofundar as análises de estabilidade da configuração de equilíbrio; para maiores detalhes acerca dessa análise, ver Setterfield (2006).

Economia e Sociedade, Campinas, v. 18, n. 2 (36), p. 237-259, ago. 2009. 
expectativas de inflação e de crescimento do produto sobre a inflação e sobre o crescimento econômico, respectivamente, assim como desconsidera a influência dos demais instrumentos de política econômica sobre os resultados econômicos. Como destacado por Montes (2008b, p. 17-18):

In the post-keynesian approach, there are many and different causes for inflation, and, hence, there are several types of inflation (see for example, Davidson, 1994; Sicsú, 2003). According to this view, the following types of inflation may be classified: (i) wage inflation, (ii) profit or degree of monopoly inflation, (iii) imported inflation, (iv) demand inflation, (v) inflation of decreasing returns to scale, (vi) tax inflation, and, (vii) inflationary shocks (such as, spot and commodity inflation). Since different types of inflation are recognized, consequently, for each type of inflation, a specific antiinflationary tool should be used.

E complementa dizendo:

The post-keynesian proposal represents mисh more than an antiinflationary macroeconomic policy. It must be faced as a permanent program against inflation which covers structural reforms, the construction of institutions and the use of specific tools of economic policy.

Vale observar que os modelos elaborados pela ortodoxia assumem a relação funcional expressa pela curva de Phillips, mas apresentam resultados distintos para a inflação e para o produto no curto e no longo prazo devido à maneira como assumem que as expectativas sejam formadas. Chick (1983, p. 311312) argumenta contra a utilidade proposta pelo mainstream à curva de Phillips:

Realizar uma discussão sobre mudanças de preços sem mencionar a curva de Phillips poderia parecer ao leitor absolutamente estranho; desde meados da década de sessenta os economistas que analisam a inflação lançam mão desta ferramenta. Há várias razões para eu não a haver utilizado. Fundamentalmente, não creio que ela se destinasse a isso. Em segundo lugar, penso que ela foi entendida como uma explicação, na crença de que o modelo de Keynes não tinha qualquer explicação para os preços, o que por sua vez, se deve ao fato de a oferta e a obtenção de lucro terem ficado fora da versão IS-LM de Keynes.

A crítica de Chick chama atenção para o fato de que assumir a curva de Phillips como instrumental explicativo para as oscilações verificadas na taxa de inflação constitui-se em aceitar um caso particular relacionado à estrutura de oferta da economia, em que o percentual de utilização da capacidade instalada atingiu o patamar que torna possível a pressão exercida pela demanda ser repassada para os preços.

A política monetária que considera ser o funcionamento da economia comportamento da inflação e do produto - compatível com o que é descrito pela curva de Phillips e, assim, lançar mão da utilização de somente um instrumento, como a taxa de juros, para controlar qualquer tipo de inflação tende a punir a produção e o emprego. Numa economia de mercado, nada garante o pleno 
Política monetária, inflação e crescimento econômico: a influência da reputação da autoridade monetária...

emprego, pois empresas decidem o quanto produzir e o quanto cobrar pelo produto com base: (i) em suas expectativas quanto ao comportamento futuro da economia, e (ii) em seus objetivos. Como sugerido por Montes (2008b, p. 10):

The economy does not have a natural tendency toward an equilibrium position; the equilibrium stability property would not prevail if expectations, though rational, may be heterogeneous. Hence, if expectations may be heterogeneous, they can also be disappointed and then mistakes can happen. Mistakes can change the parameters that sustain the equilibrium position suitable to the natural rate of unemployment. Consequently, the uniqueness property will not be valid either. ${ }^{8}$

Nesse sentido, o modelo deve ser ampliado, incorporando a influência das expectativas acerca da inflação e do produto, assim como a influência das pressões de custos sobre a inflação, com intuito de reestruturar a forma de atuação da autoridade monetária, analisando, ao mesmo tempo, a influência de sua reputação sobre a economia.

A seção seguinte se encarrega de demonstrar que a autoridade monetária, ao atuar por meio da manipulação da taxa de juros para controlar o processo inflacionário, que não seja explicado por pressão de demanda, irá atingir um resultado de equilíbrio inferior ao que seria obtido caso a política monetária fosse utilizada para atingir uma meta para o produto.

\section{Política monetária e metas para a inflação e para o produto}

A presente seção trata de apresentar um modelo que possibilita compatibilizar a condução da política monetária com metas para a inflação e para o produto. O modelo demonstra, também, que quando a autoridade monetária forma uma reputação de conduzir a política monetária por meio de uma regra voltada para o controle exclusivo da inflação, dedicando pouca ou quase nenhuma atenção para o desempenho do produto da economia, o resultado observado não é o melhor. Nesse sentido, tanto uma mudança na condução da política econômica deve ser efetuada quanto uma nova reputação da autoridade deve ser construída.

\subsection{O modelo}

O modelo é composto: (i) de uma equação de equilíbrio no mercado do produto que incorpora um termo expectacional, (ii) de uma equação para o comportamento da inflação que considera as pressões de demanda e de custos, assim como a influência das expectativas de inflação, e (iii) de uma equação de reação da autoridade monetária. Uma inovação que o modelo apresenta é a abordagem acerca da influência que a reputação da autoridade monetária exerce

(8) Para uma boa abordagem compatível com o assunto, ver Libânio (2008).

Economia e Sociedade, Campinas, v. 18, n. 2 (36), p. 237-259, ago. 2009. 
sobre as expectativas formadas para o comportamento futuro do produto por meio dos resultados observados para a inflação.

A equação (9) do modelo, equivalente ao equilíbrio no mercado do produto, é uma aproximação da equação utilizada por King (2000), contudo, pode ser entendida em termos da influência sobre o produto $(y)$ exercida pela taxa de juros $(r)$ e pelas expectativas formadas para o produto do período seguinte $\left(y_{+1}^{e}\right)-$ compatível com os resultados obtidos por Montes (2008a). Mais uma vez, o termo $A$ representa componentes autônomos, incluindo a política fiscal, assim,

$$
y=A+v_{0} y_{+1}^{e}-v_{1} r
$$

Quanto às expectativas formadas para o produto do período seguinte, são explicadas como uma função da taxa de inflação por meio do seguinte trade-off: Quando a inflação aumenta, espera-se que o produto do período seguinte se reduza e vice-versa. Ou seja, argumenta-se por uma relação inversa entre inflação $(\pi)$ e expectativas formadas para o produto do período seguinte $\left(y_{+1}^{e}\right)$, expressa pela equação (10), em que $\Omega$ simboliza um parâmetro autônomo representativo de todas as demais variáveis que afetam $\left(y_{+1}^{e}\right)$ e que, no entanto, foram omitidas do modelo

$$
y_{+1}^{e}=\Omega-\lambda . \pi
$$

A equação (10) mostra que as expectativas formadas para o produto do período seguinte são inversamente relacionadas à taxa de inflação devido à percepção dos agentes quanto às políticas econômicas que serão utilizadas para conter o processo inflacionário, assim como devido à percepção dos agentes acerca do comprometimento dos policymakers com seus objetivos. Ou seja, os agentes esperam, por exemplo, que sejam implementadas políticas econômicas que inevitavelmente levarão a uma redução do produto demandado e/ou da renda, quando a inflação se elevar - e vice-versa. Nesse sentido, pode ser estabelecida a existência de uma relação entre a reputação da autoridade monetária e o parâmetro $(\lambda)$ e, assim, sobre o desempenho da economia por meio das expectativas. ${ }^{9}$

O comportamento da inflação é apresentado pela equação (11), que informa ser a inflação explicada pelas expectativas formadas para a inflação do

(9) A confiança dos agentes se caracteriza como um elemento fundamental de propagação da política monetária pelo canal das expectativas, representando a percepção dos agentes econômicos quanto à postura da autoridade monetária e sua forma de conduzir a política monetária. Assim, uma relação pode ser estabelecida entre o "estado de expectativas" (Dequech, 1999; Montes; Feijó, 2007) - que envolve as expectativas e a confiança dos indivíduos e firmas - e a reputação e transparência da autoridade monetária e a credibilidade de suas políticas. 
período seguinte $\left(\pi_{+1}^{e}\right)$, por pressões de demanda $\left(y^{d}\right)$ e por pressões de custos $(Z) .^{10}$

$$
\pi=\alpha_{0} \pi_{+1}^{e}+\alpha_{1} y^{d}+Z
$$

Os custos, por sua vez, podem ser explicados por meio da seguinte função: $Z=g(\dot{\varepsilon}, \dot{W}, \Lambda) \cdot{ }^{11}$ Assim, na equação $(12),(\dot{\varepsilon})$ representa as variações na taxa de câmbio nominal, $(\dot{W})$ representa a variação dos salários nominais e $(\Lambda)$ a produtividade média do trabalho, sendo

$$
Z=\alpha_{2} \dot{\varepsilon}_{t}+\alpha_{3} \dot{W}_{t}-\alpha_{4} \Lambda
$$

Por outro lado, a influência do produto demandado sobre a taxa de inflação pode ser entendida por meio da análise do grau de utilização da capacidade instalada, comparando o produto da economia com o produto crítico $^{12}$ e o produto de pleno emprego. O modelo sugere essa análise para explicar os impactos das pressões de demanda sobre a inflação. Sendo assim, se a economia estiver em uma situação na qual o produto observado é menor do que o produto crítico, então, uma elevação do produto demandado não irá se traduzir em elevação da inflação. Porém, se a economia estiver em uma situação em que o

(10) Acerca da influência que exercem as expectativas formadas para a inflação do período seguinte sobre o comportamento da inflação e seu papel no regime de meta de inflação, assim como os elementos determinantes dessas expectativas, ver a Seção 2.2.

(11) A influência das variações da taxa nominal de câmbio ( $\dot{\mathcal{E}}$ ) sobre a inflação será maior ou menor de acordo com o grau de dependência e/ou de utilização de produtos importados. Ou seja, se o peso das importações no processo produtivo for expressivo, maiores serão os repasses de variações do câmbio para os preços. Além disso, quanto mais intensos e voláteis forem os fluxos comerciais e financeiros entre o país e o resto do mundo, mais suscetível estará o câmbio a sofrer oscilações, e consequentemente, maior será a variabilidade da taxa de inflação. Quanto às pressões sobre a taxa de inflação resultantes de alterações nos salários nominais $(\dot{W})$, essas serão maiores ou menores de acordo com a magnitude do impacto que tais alterações nos salários exerçam sobre os custos das firmas. Nesse sentido, dependendo da variação dos salários nominais, as firmas podem absorver o impacto caso não afete significativamente seus negócios e suas estratégias, implicando, nesse sentido, a alteração do seu mark up em alguma medida, ou podem incorrer em repasses para os preços no caso de terem, generalizadamente, suas estratégias e seus objetivos afetados. Além disso, é tradicionalmente reconhecido que, quando o hiato do emprego é reduzido (elevado) fica mais fácil (difícil) para os trabalhadores obterem aumentos (reduções) salariais, que se traduzem em maior facilidade para as firmas repassarem esse aumento em seus custos para os preços (ou se traduzem na possibilidade das firmas repassarem essas reduções nos custos para os preços). Deve ser observado, entretanto, que um aumento de salário não se reverterá em um aumento da inflação caso seja acompanhado por um aumento da produtividade do trabalho. A produtividade do trabalho, por sua vez, influencia no comportamento da taxa de inflação por meio dos custos. Dado que o custo marginal do trabalho e o custo médio do trabalho têm seus comportamentos explicados pelo produto marginal do trabalho e pelo produto médio do trabalho de forma inversa, respectivamente.

(12) O produto crítico é uma situação em que o nível do produto que se observa na economia é resultado de uma elevada utilização da capacidade instalada, ou seja, um nível de produto que se encontra muito próximo ao produto de pleno emprego. Uma economia operando no nível do produto crítico, ou além desse, pode vir a observar um aumento generalizado dos preços, caso a demanda da economia esteja se elevando. 
produto observado se encontra em um nível entre o produto crítico e o produto de pleno emprego, então, uma elevação da demanda, embora estimule o produto, poderá se reverter, também, em uma elevação da inflação. Há, além desses casos, a situação em que o produto observado equivale ao produto de pleno emprego, isto é, existe plena utilização da capacidade instalada, dessa forma, caso a demanda agregada aumente a inflação também irá se elevar. Assim,

$$
\left\{\begin{array}{l}
y<y^{c}, \quad \text { então, } \quad \alpha_{1}=0 \leftrightarrow \Delta y^{d}>0 \text { e, } \alpha_{1}>0 \leftrightarrow \Delta y^{d}<0 \\
\operatorname{Se} \quad y^{c}<y<y^{p}, \quad \text { então, } \quad \alpha_{1}=i, \text { em que } i \in \mathfrak{R}_{+} \\
y \geq y^{p}, \quad \text { então, } \quad \alpha_{1}=i+j, \text { em que } j \in \mathfrak{R}_{+}^{*}
\end{array}\right.
$$

$\mathrm{O}$ primeiro caso indica que, em uma situação na qual o produto da economia é menor do que o produto crítico, quando verificada uma variação positiva do produto demandado, essa não irá se reverter em um aumento da inflação, contudo, uma variação negativa do produto demandado irá resultar em uma redução da inflação. Esse comportamento pode ser explicado pelo fato de as firmas estarem preocupadas em conquistar maiores fatias de mercado, dessa forma, quando estimuladas a produzirem mais devido a um aumento da demanda e dado que operam com elevada capacidade ociosa, não repassarão as pressões de demanda para os preços por uma questão estratégica. Por outro lado, quando a demanda da economia se reduz e a produção já se encontra realizada, uma maneira de as firmas reduzirem seus estoques, não deixando que se acumulem, é por meio da redução dos preços, o que se reverte em uma diminuição da inflação.

O segundo caso pode ser entendido como uma situação em que pressões de demanda podem ou não se reverterem em aumentos da inflação. As firmas, nesse caso, quando observam aumentos da demanda, podem optar por não aumentarem os preços, tanto por uma questão estratégica quanto por acreditarem que os policymakers irão atuar por meio de políticas de retração da demanda. No entanto, podem promover aumentos dos preços - de acordo com o seu poder de mercado - se esses não atrapalharem seus objetivos de longo prazo e/ou se acreditarem que os policymakers não irão atuar de maneira austera quanto ao comportamento da inflação.

O terceiro caso representa uma situação em que o produto da economia equivale ao produto de pleno emprego. Sendo assim, enquanto o produto demandado estiver se elevando, as firmas, de maneira generalizada, dado que se encontram operando no potencial de sua capacidade instalada, responderão por meio de elevações dos preços.

Quanto à reação da autoridade monetária com base em manipulações da taxa de juros mediante desvios dos resultados observados em relação aos seus 
respectivos objetivos (meta de inflação e meta de crescimento econômico), essa é representada pela seguinte equação:

$$
\dot{r}=\ell_{0}\left(\pi-\pi^{T}\right)+\ell_{1}\left(y-y^{T}\right)
$$

A equação (13) pode ser assim entendida: a autoridade monetária irá reagir promovendo variações na taxa de juros quando a taxa de inflação se desviar da meta de inflação e/ou quando o nível do produto se desviar da meta para o nível do produto. No modelo aqui proposto, a autoridade monetária somente reage aos desvios da inflação em relação à meta, manipulando a taxa de juros, quando a inflação for de demanda. A proposta, portanto, é a autoridade monetária atuar manipulando a taxa de juros com intuito de controlar a inflação resultante de pressões exercidas pela demanda e/ou para fazer com que o produto observado convirja para a meta do produto. Nesse sentido, para o caso de uma inflação de custos, não sendo, portanto, a pressão inflacionária explicada pela demanda, então, $\ell_{0}=0$. Com isso, a autoridade monetária não irá promover manipulações na taxa de juros para controlar a inflação, sendo a equação de reação simplificada para

$$
\dot{r}=\ell_{1}\left(y-y^{T}\right)
$$

Diferenciando em relação ao tempo as equações (9), (10) e (11), são obtidas as respectivas equações:

$$
\begin{aligned}
& \dot{y}=\dot{A}+v_{0} \dot{y}_{+1}^{e}-v_{1} \dot{r} \\
& \dot{y}_{+1}^{e}=-\lambda . \dot{\pi} \\
& \dot{\pi}=\alpha_{0} \dot{\pi}_{+1}^{e}+\alpha_{1} \dot{y}^{d}+\dot{Z}
\end{aligned}
$$

Substituindo as equações (13) e (15) na equação (14), obtém-se

$$
\dot{y}=\dot{A}-v_{0} \dot{\pi} \cdot \dot{\pi}-v_{1}\left[\ell_{0}\left(\pi-\pi^{T}\right)+\ell_{1}\left(y-y^{T}\right)\right]
$$

Por outro lado, substituindo as equações (13’) e (15) na equação (14), obtém-se a seguinte expressão:

$$
\dot{y}=\dot{A}-v_{0} \dot{\pi} \cdot \dot{\pi}-v_{1}\left[\ell_{1}\left(y-y^{T}\right)\right]
$$

Por meio da condição de equilíbrio, $\dot{y}=\dot{\pi}=0$, admitindo $\dot{A}=0$ e resolvendo as equações (17) e (17') para y, são obtidas as equações (18) e (18'), respectivamente,

$$
y=-\frac{\ell_{0}}{\ell_{1}}\left(\pi-\pi^{T}\right)+y^{T}
$$




$$
y=y^{T}
$$

Os resultados mostram que, quando a autoridade monetária utiliza a taxa de juros para perseguir uma meta para o produto, consegue fazer convergir o produto observado para a sua meta, equação (18'). Contudo, quando busca controlar a inflação por meio de manipulações da taxa de juros quando, por exemplo, a taxa de inflação se encontra acima da meta de inflação, o resultado obtido para o produto é inferior, pois apresenta um produto se desviando (para baixo) da meta para o produto, como mostra a equação (18).

\subsection{Expectativas de inflação e o papel da meta de inflação}

A utilização de uma meta para a inflação serve como um guia para formação das expectativas de inflação, que, em última instância, induz a taxa de inflação observada a convergir para a meta.

Os agentes econômicos, ao estabelecerem relações entre si, tomam como base para suas decisões uma série de expectativas formadas para diferentes variáveis capazes de afetar os resultados de seus negócios. Uma das variáveis de grande importância para o processo de decisões dos agentes são as expectativas formadas para a inflação. Sua importância pode ser atribuída, por exemplo, à necessidade de os agentes estarem a todo instante buscando manter ou aumentar suas participações no processo de formação e distribuição do produto e da renda da economia. Assim, ao tomarem suas decisões relacionadas ao processo de formação de preços com base nas expectativas formadas para a inflação, os agentes buscam se utilizar das informações e do conhecimento que regem essas expectativas de modo a minimizarem eventuais perdas que possam vir a ocorrer em seus negócios e que inevitavelmente levariam a reduzir suas participações na renda da economia.

Se, de fato, os agentes tomam suas decisões sendo fortemente influenciados pelas expectativas, podem acabar sancionando essas expectativas, tornando-as uma profecia autorrealizável. Nesse sentido, um entendimento acerca dos determinantes fundamentais das expectativas de inflação torna-se crucial para a forma de conduzir a política monetária. A equação representativa do comportamento das expectativas formadas para a inflação é dada por ${ }^{13}$

$$
\pi_{+1}^{e}=\beta_{1} \dot{\pi}_{t-1}+\beta_{2} \pi_{t}^{T}-\beta_{3} \dot{\wp}_{t-1}-\beta_{4} \dot{r}_{t-1}+\beta_{5} \dot{W}_{t}^{e}+\beta_{6} \dot{\varepsilon}_{t}^{e}
$$

(13) A equação (19) tem como referencial teórico o trabalho de Cerisola e Gelos (2005). A equação aqui sugerida combina tanto elementos backward-looking quanto elementos forward-looking, no entanto, enquanto na equação de Cerisola e Gelos existe uma predominância de elementos backward-looking explicando o comportamento das expectativas formadas para a inflação, a equação aqui apresentada possui uma maior quantidade de elementos forward-looking, baseados em expectativas. 
Em que $\left(\dot{\pi}_{t-1}\right)$ representa a influência exercida pelas variações da inflação observada no período $t-1,\left(\pi_{t}^{T}\right)$ é a meta de inflação para o período $t,\left(\dot{\wp}_{t-1}\right)$ representa a influência das variações no superávit fiscal primário em $t-1,\left(\dot{r}_{t-1}\right)$ sugere a influência da política monetária por meio de alterações da taxa de juros observadas no período $t-1,\left(\dot{W}_{t}^{e}\right)$ representa o impacto das expectativas formadas em $t-1$ para as variações dos salários nominais que irão ocorrer em $t$, e, $\left(\dot{\varepsilon}_{t}^{e}\right)$ representa o impacto das expectativas formadas em $t-1$ para as variações na taxa de câmbio nominal no período $t^{14}$

A importância da equação (19) no modelo se deve basicamente a dois motivos: 1) as expectativas de inflação desempenham um papel fundamental para o regime de metas de inflação, pois os policymakers buscam fazer convergir as expectativas de inflação para a meta de inflação; 2) a equação mostra que existem outras políticas, além da monetária, capazes de afetar as expectativas de inflação e, com isso, o comportamento da inflação.

Tradicionalmente, são reconhecidos os impactos (i) da inflação passada, (ii) da política monetária implementada no passado e (iii) dos resultados primários (deficit/superavit) do governo sobre as expectativas formadas para a inflação. Existe, portanto, o efeito exercido pela inflação passada sobre as expectativas de inflação, explicado pelas revisões que os agentes realizam em suas expectativas adaptando-as - e conferindo, dessa maneira, um caráter inercial à dinâmica inflacionária, assim como o efeito das políticas econômicas sobre as expectativas de inflação. ${ }^{15}$

Quanto às variações nas expectativas formadas para os salários nominais e para a taxa de câmbio, essas, por sua vez, refletem as expectativas formadas para possíveis variações nos custos das firmas. Se as firmas acreditam, com base em suas expectativas, que serão afetadas por modificações em seus custos, antes que sofram possíveis perdas, acabam se antecipando por meio de alterações nos seus preços na tentativa de manterem suas participações na renda da economia, evitando redistribuições indesejáveis e, assim, sancionando o processo inflacionário.

A equação capta, também, a influência do regime de metas de inflação sobre as expectativas de inflação, isto é, quanto mais crível for o regime de metas de inflação e as políticas monetárias utilizadas, assim como quanto mais bem

(14) Embora a reputação da autoridade monetária seja capaz, também, de afetar os parâmetros ( $\beta$, s), o trabalho não tem como preocupação enfatizar tal ponto, mas, sim, o parâmetro da equação (10), como será visto mais detalhadamente na seção seguinte (2.3).

(15) As políticas econômicas afetam a economia não somente por meio de alterações na demanda agregada, mas também por meio das expectativas formadas para a inflação.

Economia e Sociedade, Campinas, v. 18, n. 2 (36), p. 237-259, ago. 2009. 
definida e mais forte for a reputação da autoridade monetária, maior será a influência da meta de inflação sobre as expectativas de inflação formadas pelos agentes. Nesse sentido, mais próximo de um estará o parâmetro explicativo dessa variável (ou seja, $\beta_{2} \rightarrow 1$ ), indicando que a meta estabelecida para a inflação, ceteris paribus, está atingindo um de seus objetivos: servir como âncora para as expectativas de inflação, ou seja, fazer as expectativas de inflação e, por conseguinte, a inflação observada convergirem para a meta.

No entanto, a convergência das expectativas de inflação e, por conseguinte, da inflação observada para a meta de inflação depende, em certo grau, da leitura que os agentes façam acerca da influência das políticas econômicas sobre o comportamento dos preços na economia. Pela equação (19) é mostrado que tanto a política fiscal (pelo superávit primário) quanto a política monetária (pela taxa de juros) exercem influência sobre as expectativas de inflação. A convergência da inflação e das expectativas para a meta será uma função tanto do comprometimento do policymaker com os seus objetivos e das políticas que implementa para atingi-los, quanto da crença do público acerca desse comprometimento (medido por meio de sua reputação) e da credibilidade das políticas que põe em prática. Embora a manipulação da taxa de juros leve a resultados antagônicos entre objetivos - pois, por mais que o aumento da taxa de juros, por exemplo, auxilie no processo de redução da inflação, por outro lado, traz resultados adversos para o produto - não necessariamente os objetivos estabelecem um trade-off entre si, como busca mostrar a curva de Phillips. O modelo mostra que o processo inflacionário não sanciona o crescimento econômico e a redução do desemprego. Entretanto, o crescimento econômico, de acordo com a evolução do produto demandado, pode vir a ser capaz de pressionar a inflação, desde que sejam verificadas as situações acerca do grau de utilização da capacidade instalada. Sendo assim, a manipulação da taxa de juros como forma de controlar a inflação deve ser entendida com um recurso para o caso específico de inflação de demanda e, ainda assim, sendo implementada de maneira parcimoniosa e coordenada com a política fiscal.

A autoridade monetária deve buscar estabelecer, portanto, a reputação de estar atuando tanto na busca da estabilização da inflação, quanto na busca de uma meta para o produto, ou seja, de ser tanto guardiã da moeda quanto indutora do crescimento econômico. Os agentes econômicos devem ser levados a crer, por meio da reputação estabelecida pela autoridade monetária, que na medida em que a inflação der sinais de estar se desviando da meta, quando diagnosticada por pressões de demanda, a autoridade monetária irá atuar de maneira austera manipulando a taxa de juros. Essa crença faria os agentes econômicos reverem suas expectativas e, assim, levaria a inflação a convergir novamente para a meta. Os agentes econômicos devem ser levados a crer, também, que, ao ser verificado 
um ambiente estável de preços com inflação baixa, a autoridade monetária irá atuar de modo a induzir a aplicação de recursos em ativos produtivos, estimulando os investimentos e, assim, o crescimento econômico. Sendo assim, a autoridade monetária que apresenta uma elevada (forte) reputação de ser uma instituição preocupada com a inflação, mas também com os resultados observados na esfera real, ao atuar por meio da implementação de políticas críveis e de forma transparente, irá fazer com que o conhecimento dos indivíduos acerca do funcionamento da economia e da forma de atuação da autoridade monetária, decidindo sob incerteza não probabilística, se amplie. Nesse sentido, com maiores e melhores informações e um conhecimento mais amplo, a percepção à incerteza se reduz, aumentado a confiança nas expectativas formadas acerca de acontecimentos futuros e, consequentemente, gerando um "estado de expectativas" otimista. Tal otimismo se reflete na escolha por um portfólio de ativos voltado para obtenção de ganhos de longo prazo, ou seja, estimulando a escolha por ativos reais (investimentos), reduzindo a preferência pela liquidez e, assim, estimulando o produto e a renda da economia.

Quanto aos desvios da inflação em relação à meta, explicados por pressões de custos, não devem ser resolvidos utilizando políticas que atuam sobre a demanda agregada - como a política monetária via taxa de juros - mas sim, atacando o foco da questão - que são os custos. Políticas de rendas assim como políticas comerciais e intervenções no mercado de câmbio por parte da autoridade monetária podem surtir efeito sobre os custos e serem eficazes em controlar a inflação, trazendo ao mesmo tempo resultados menos indesejados em termos de produto, emprego e renda. ${ }^{16}$

\subsection{Reputação, política monetária e desempenho econômico}

Acerca da importância da reputação da autoridade monetária para o desempenho da economia, o parâmetro $(\lambda)$ da equação (10) capta a influência dessa reputação sobre as expectativas formadas para o produto do período seguinte $\left(y_{+1}^{e}\right)$ quando são verificadas alterações na taxa de inflação $(\pi)$. Espera-se, por exemplo, que, quanto maior for a importância atribuída aos resultados observados para o produto pela autoridade monetária - possuindo, portanto, a reputação de ser uma instituição preocupada em afetar o lado real da economia, buscando, assim, melhorar o desempenho em termos de produto e renda -, menor será a influência da inflação sobre as expectativas formadas para o produto do período seguinte, indicando, nesse sentido, um parâmetro $(\lambda)$ com um baixo valor. Portanto, ao se verificar uma alteração na taxa de inflação, essa não trará como consequência um impacto adverso tão forte sobre o produto da economia quanto aquele que seria

(16) Para maiores detalhes acerca das possíveis políticas que possam ser adotadas para combater a inflação, ver Sicsú (2003).

Economia e Sociedade, Campinas, v. 18, n. 2 (36), p. 237-259, ago. 2009. 
observado, caso a autoridade monetária possuísse a reputação de ser uma instituição preocupada única e exclusivamente com a inflação.

Chamando de reputação do tipo I a autoridade monetária que atua conforme a hipótese de não neutralidade da moeda - sendo a política monetária capaz de afetar tanto o lado nominal quanto o lado real da economia - e de reputação do tipo II a autoridade monetária que atua conforme a hipótese de neutralidade da moeda - sendo a política monetária implementada com o intuito de atuar sobre as variáveis nominais conforme uma regra de manipulação da taxa de juros para controlar somente a inflação, não importando a origem do processo inflacionário - então, pelo modelo, as alterações no produto em decorrência de oscilações na taxa de inflação e da reação da autoridade monetária podem ser comparadas e analisadas.

Tais alterações no produto serão analisadas com base na seguinte hipótese acerca da influência da reputação da autoridade monetária sobre o desempenho da economia: as variações nas expectativas formadas para o produto, explicadas por variações na inflação, são maiores quando a reputação da autoridade monetária for do tipo II, e, as variações nas expectativas formadas para o produto, explicadas por variações na inflação, serão menores quando a reputação da autoridade monetária for do tipo I, o que equivale a $\lambda_{\text {tipoII }}>\lambda_{\text {tipol }}$.

As equações (20), (21) e (22) são obtidas das equações (14) e (15). A equação (20) representa o caso em que a autoridade monetária não utiliza a taxa de juros para controlar a inflação de custos e possui uma reputação do tipo I; a equação (21) representa o caso em que a autoridade monetária utiliza a taxa de juros para controlar a inflação, seja ela qual for, e possui uma reputação do tipo II; e a equação (22) representa o caso de uma autoridade monetária com reputação do tipo I que utiliza a taxa de juros para controlar a inflação de demanda.

$$
\begin{aligned}
& \dot{y}=\dot{A}-v_{0} \lambda_{\text {tipol }} \cdot \dot{\pi} \\
& \dot{y}=\dot{A}-v_{0} \lambda_{\text {tipoII }} \cdot \dot{\pi}-v_{1} \cdot \dot{r} \\
& \dot{y}=\dot{A}-v_{0} \lambda_{\text {tipoI }} \cdot \dot{\pi}-v_{1} \cdot \dot{r}
\end{aligned}
$$

Para o caso de uma taxa de inflação se elevando e acelerando, os resultados, em termos de variação no produto, mostram que é melhor a autoridade monetária possuir uma reputação do tipo I do que uma reputação do tipo II. Pelo fato de $\lambda_{\text {tipoII }}>\lambda_{\text {tipol }}$, então, mesmo se a autoridade monetária não buscasse controlar o aumento na variação da taxa de inflação pela manipulação da taxa de juros, o resultado, em termos de variação do produto, seria pior, para o caso de uma autoridade monetária com reputação do tipo II, pois geraria um estado de 
expectativas pessimistas em relação ao comportamento do produto no futuro, devido, justamente, à reputação ostentada pela autoridade monetária.

Nesse sentido, o resultado apresentado pela equação (21) é pior do que os resultados apresentados pelas equações (20) e (22), por dois motivos: 1) a aceleração da inflação trará uma redução maior em $\dot{y}$, devido à reputação da autoridade monetária, ou seja, $\lambda_{\text {tipolI }}>\lambda_{\text {tipol }}$; e 2) pelo fato de a autoridade monetária reagir aumentando a taxa de juros, isso faz com que $\dot{y}$ se reduza mais ainda.

Para o caso de uma inflação de custos, o melhor que a autoridade monetária faz (em termos de resultados para o produto) é possuir uma reputação do tipo I e não combater a inflação pela elevação da taxa de juros, conforme a equação (20). Deve ser lembrado que uma taxa de juros mais elevada implica um custo financeiro maior, o que dá margem às firmas repassarem esses custos para os preços. Caso a autoridade monetária possua uma reputação do tipo I, porém atue combatendo a inflação de custos aumentando a taxa de juros - conforme a equação (22) - com o tempo, e se assim for de maneira recorrente, isso enfraquecerá sua reputação do tipo I, levando à construção de uma reputação do tipo II.

No caso de uma inflação de demanda, não há restrição para o uso da taxa de juros como forma de reduzir a taxa de inflação, desde que seja feita de maneira comedida e coordenada com as demais políticas econômicas, e implementada por uma autoridade monetária com reputação do tipo I.

Em um mundo onde decisões são tomadas com base em expectativas sobre um futuro incerto, instituições são criadas para dar confiança às expectativas e com isso viabilizar as operações econômicas. Dentre as instituições mais importantes numa economia monetária de produção encontram-se a autoridade monetária e suas políticas. Exatamente pela sua capacidade de influir em resultados reais na economia, a sua gestão é determinante para a estabilidade do estado de expectativas. Nesse sentido, a reputação que a autoridade monetária constrói se caracteriza como um elemento determinante para o processo de tomada de decisões dos agentes que operam em uma economia. Ao estabelecer certa reputação, a autoridade monetária induz os agentes econômicos a tomarem decisões conforme as expectativas que formam acerca de sua reação. Sua reputação, portanto, é fundamental para o conhecimento dos agentes acerca do modo como a autoridade monetária enxerga o funcionamento da economia e do modo como reage a distúrbios que nela ocorrem.

Com base no modelo, a autoridade monetária deve, em primeiro lugar, reconhecer que suas políticas são capazes de afetar tanto a esfera nominal quanto a 
esfera real da economia ${ }^{17}$ e, nesse sentido, assumir uma postura compatível com a sua capacidade de promover a estabilização tanto dos preços quanto do produto, atuando por meio de políticas coordenadas com as demais políticas econômicas. Deve criar, assim, a reputação de ser uma instituição não somente preocupada em controlar a inflação, mas a reputação de ser uma instituição que atua de acordo com as necessidades levantadas pela sociedade, quer sejam associadas com o lado real ou o lado nominal da economia. A "política monetária é uma política de governo, a ser decidida juntamente com as outras políticas de governo. O Banco Central não é um poder à parte, nem é capaz de isolar sua área de influência das outras áreas da economia" (Carvalho, 2005, p. 335).

\section{Considerações finais}

Embora o mainstream econômico reconheça a existência de outras pressões inflacionárias que não somente a de demanda, seus modelos de funcionamento da economia e consequente reação da autoridade monetária encontram-se fundamentados na relação expressa pela curva de Phillips. Independentemente de os modelos estarem adotando a versão aceleracionista com expectativas adaptativas - ou a versão novo-clássica/novo-keynesiana - com expectativas racionais -, partem do princípio de que toda inflação é explicada por pressões de demanda e que, no longo prazo, o produto encontrar-se-á em sua taxa natural - compatível com a Nairu. Nesse sentido, com base na hipótese de neutralidade da moeda no longo prazo, sugerem que a autoridade monetária deve voltar seus esforços para o alcance de um único objetivo: a manutenção da taxa de inflação em um patamar baixo e estável, não devendo, portanto, voltar suas políticas para a obtenção de resultados reais.

Contudo, a adoção de uma regra de reação da autoridade monetária, por meio de manipulações da taxa de juros, sob o regime de metas de inflação sustentada pela hipótese de neutralidade da moeda e pelo resultado de equilíbrio compatível com a Nairu - vem apresentando resultados controversos para a economia brasileira. A reputação sendo criada pela autoridade monetária, compatível com as ideias sustentadas pelo "Novo consenso", vem se traduzindo em um estrangulamento cada vez mais acentuado das taxas de crescimento da economia brasileira, além de estar gradativamente reduzindo o produto potencial, por meio das baixas taxas de investimento verificadas.

(17) A política monetária traz impactos sobre o mercado de ativos por meio de mudanças na taxa de juros e, por conseguinte, nos preços dos ativos financeiros, o que induz modificações na escolha do portfólio desejado de ativos. Dado que a posse de ativos (reais ou financeiros) é um veículo para a acumulação de riqueza, então, no que a política monetária é implementada, as decisões de investimento são afetadas, trazendo consequências para os resultados reais no longo prazo. Para maiores detalhes acerca da influência da política monetária sobre o lado real tanto no curto quanto no longo prazo, ver Carvalho (2005) e Carvalho et al. (2000). 
Não importa qual seja o motivo que levou a inflação a se elevar (se pressões de demanda, de custos ou pelas expectativas formadas para a inflação), o modelo proposto na Seção 3 mostra que, quando a autoridade monetária possui a reputação de ter como principal e único objetivo o controle da inflação, ao manipular seu principal instrumento - a taxa de juros - com intuito de estabilizar a inflação, os custos da desinflação, em termos de resultados observados para o produto, serão maiores.

Os resultados obtidos baseados no modelo apresentado na Seção 3 são amplamente compatíveis com a noção de que a política monetária seja capaz de afetar tanto variáveis nominais quanto variáveis reais, ou seja, com a hipótese de não neutralidade da moeda. Nesse sentido, como aponta Carvalho (2005, p. 334335):

A política monetária, como as outras políticas de administração de demanda agregada, afeta tanto os níveis de preços quanto o nível de atividade e a taxa de crescimento da economia (ao afetar a decisão de investir). Pelas razões apresentadas, é provável que a política monetária seja mais importante para influenciar o crescimento da economia que a política fiscal. Por isso, uma primeira conclusão importante é a de que a política monetária é uma política de governo, a ser decidida juntamente com as outras políticas de governo.

Pelo modelo proposto, o trabalho mostrou, de forma inovadora, que o crescimento econômico não é estimulado pela inflação, e que a autoridade monetária ao sustentar uma reputação baseada no princípio da neutralidade da moeda, implementando sua política monetária com base em uma regra de elevações da taxa de juros para conter as pressões inflacionárias, somente estrangula o crescimento econômico. O uso da taxa de juros, como forma de combater o processo inflacionário, deve ser parcimonioso e estar de acordo com o diagnóstico preciso de inflação. $O$ trabalho mostrou, também, que a reputação da autoridade monetária configura-se em um importante elemento explicativo dos resultados obtidos na economia quando políticas monetárias são implementadas.

\section{Referências bibliográficas}

ANGERIZ, A.; ARESTIS, P. Has inflation targeting had any impact on inflation? Journal of Post Keynesian Economics, v. 28, n. 4, p. 559, Summer 2006.

ALLSOPP, C.; VINES, D. The assessment: macroeconomic policy. Oxford Review of Economic Policy, v. 14, n. 4, 2000.

CARVAlHO, F. C. et al. Economia Monetária e Financeira: teoria e política. Rio de Janeiro: Editora Campus, 2000.

Uma contribuição ao debate em torno da eficácia da política monetária e algumas implicações para o caso do Brasil. Revista de Economia Política, v. 25, n. 4, out./dez. 2005. 
CERISOLA, M.; GELOS, R. G. What drives inflation expectations in Brazil? An empirical analysis". International Monetary Fund, 2005. (IMF Working Paper, WP/05/109).

CHICK, V. Macroeconomia após Keynes. Forense Universitária, 1983.

DAVIDSON, P. Post Keynesian macroeconomic theory. Cheltenhan: Edward Elgar, 1994.

DEQUECH, D. Expectations and confidence under uncertainty. Journal of Post Keynesian Economics, v. 21, n. 3, Spring 1999.

GOODFRIEND, M. Monetary policy in the new neoclassical synthesis: a primer. Federal Reserve Bank of Richmond Economic Quarterly, v. 90, n. 3, Summer 2004.

; KING, R. G. The new neoclassical synthesis and the role of monetary policy. In: BERNANKE, Ben; ROTEMBERG, Julio (Ed.). NBER Macroeconomics Annual. Cambridge, Ma: MIT Press, 1997.

KING, R. G. The new IS-LM model: language, logic, and limits. Federal Reserve Bank of Richmond Economic Quarterly, v. 86, n. 3, Summer 2000.

LAVOIE, M. A post keynesian amendment to the new consensus on monetary policy. Metroeconomica, v. 57, n. 2, 2006.

LEEPER, E. M.; SIMS, C. Toward a modern macroeconomic model usable for policy analysis. Jun. 1994. (NBER Working Paper, n. 4761).

LIBÂNIO, G. Aggregate demand and the endogeneity of the natural rate of growth: evidence from Latin American economies. In: ENCONTRO INTERNACIONAL DA ASSOCIAÇÃO KEYNESIANA BRASILEIRA, 1, UNICAMP-Campinas, abr. 2008.

LUCAS JR., R. E. Expectations and the neutrality of money. Journal of Economics Theory, v. 4, Apr. 1972a.

Econometric testing of the natural rate hypothesis. In: ECKSTEIN, Otto (Ed.). The econometrics of price determination. Washington: Board of Governors of the Federal Reserve System, 1972b.

Econometric policy evaluation: a critique. In: BRUNNER, Karl; MELTZER, Allan H. (Ed.). The Phillips curve and labor markets. Carnegie-Rochester Conference Series on Public Policy, 1976. v. 1.

Methods and problems in business cycle theory. Journal of Money, Credit, and Banking, v. 12, Nov. 1980.

MISHKIN, F. S. Can inflation targeting work in emerging market countries? 2004. (NBER Working Papers Series, WP 10646). Disponível em: $<$ http://www.nber.org/papers/w10646>.

MONTES, G. C. Metas de inflação em perspectiva: a influência do trinômio reputaçãocredibilidade-transparência sobre a economia. Revista de Economia Política, 2008a. (a ser publicado). 
Política monetária, inflação e crescimento econômico: a influência da reputação da autoridade monetária...

MONTES, G. C. Reputation, credibility and monetary policy effectiveness. In: ENCONTRO INTERNACIONAL DA ASSOCIAÇÃO KEYNESIANA BRASILEIRA, 1, UNICAMP-Campinas, Abr. 2008b.

; FEIJÓ, C. A. Reputação, credibilidade e transparência da autoridade monetária e o Estado de expectativa. Economia e Sociedade, Campinas, v. 16, n. 2 (30), ago. 2007.

ROMER, D. Keynesian macroeconomics without the LM curve. Journal of Economic Perspectives, v. 14, n. 2, Spring 2000.

SETTERFIELD, M. Is inflation targeting compatible with post keynesian economics? Journal of Post Keynesian Economics, v. 28, n. 4, Summer 2006.

SICSÚ, J. Políticas não-monetárias de controle da inflação: uma proposta pós-keynesiana. Revista Análise Econômica, ano 21, n. 39, jan./mar. 2003.

SIMS, C. Macroeconomics and reality. Econometrica, v. 48, jan. 1980.

TAYLOR, J. B. Teaching modern macroeconomics at the principles level. American Economic Review, v. 90, n. 2, 2000.

WOODFORD, M. Interest and prices: foundations of a theory of monetary policy. Princeton: Princeton University Press, 2003. 